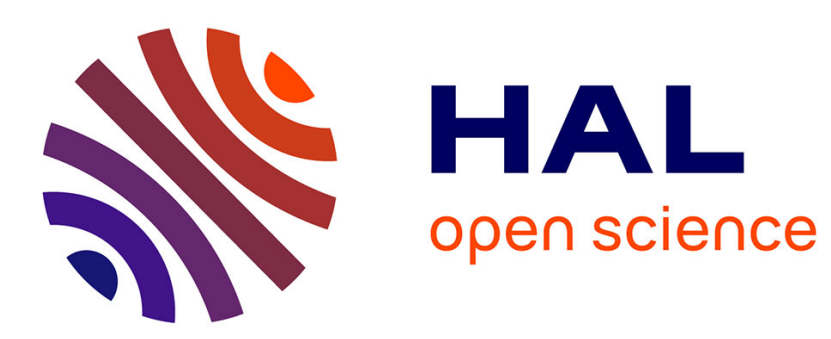

\title{
Flat foam-based Mikaelian lens antenna for millimeter wave applications
}

\author{
Jonathan Bor, Benjamin Fuchs, Olivier Lafond, Mohamed Himdi
}

\section{To cite this version:}

Jonathan Bor, Benjamin Fuchs, Olivier Lafond, Mohamed Himdi. Flat foam-based Mikaelian lens antenna for millimeter wave applications. European Radar Conference, Oct 2014, Rome, Italy. pp.15, 10.1109/EuRAD.2014.6991276 . hal-01136235

\section{HAL Id: hal-01136235 \\ https://hal.science/hal-01136235}

Submitted on 26 Mar 2015

HAL is a multi-disciplinary open access archive for the deposit and dissemination of scientific research documents, whether they are published or not. The documents may come from teaching and research institutions in France or abroad, or from public or private research centers.
L'archive ouverte pluridisciplinaire HAL, est destinée au dépôt et à la diffusion de documents scientifiques de niveau recherche, publiés ou non, émanant des établissements d'enseignement et de recherche français ou étrangers, des laboratoires publics ou privés. 


\title{
Flat Foam-based Mikaelian Lens Antenna for Millimeter Wave Applications
}

\author{
Jonathan Bor, Benjamin Fuchs, Olivier Lafond and Mohamed Himdi \\ University of Rennes 1 - IETR, Rennes, France \\ Email: \{jonathan.bor;benjamin.fuchs;olivier.lafond;mohamed.himdi\}@univ-rennes1.fr
}

\begin{abstract}
The design principles and radiation performances of Mikaelian lens antennas are investigated. An innovative technique to manufacture gradient index lenses based on the variation of the foam density is described and applied to Mikaelian lenses. This yields low cost and lightweight lenses. The radiation performances of a foam-based planar Mikaelian lens antenna are simulated and measured at $60 \mathrm{GHz}$. They validate the foam technique and show the potentialities of such lens antennas.
\end{abstract}

\section{INTRODUCTION}

Gradient index lens antennas have many interesting features such as their broadband behavior, ability to form multiple beams (especially for the Luneburg lens) and reasonable weight (as the frequency increases). They are therefore a good candidate for many applications [1]-[3].

In this paper, we present a gradient index lens that has, despite its many merits, not been exhaustively reported in the literature: the Mikaelian lens [4], [5]. This cylindrical lens can be seen as a section of an optical fiber as represented in Fig. 1(a).

The main difference of the Mikaelian lens with respect to the Luneburg and half Maxwell fish-eye lens is its flat shape (base of the cylinder) which eases its integration to a primary source. The paper is organized as follows. The properties of Mikaelian lenses are first presented. The different ways to manufacture gradient index lenses are briefly reviewed and a novel foam based technique is described. The radiation performances of a Mikaelian lens are numerically and experimentally characterized at $60 \mathrm{GHz}$. Conclusions are drawn in Section V.

\section{Properties of Mikaelian Lenses}

The Mikaelian lens is a cylindrical lens of thickness $T$ and radius $R$ (see Fig. 1(b)). Its refractive index varies with the radial distance $r$ according to the following equation:

$$
n(r)=\frac{n(0)}{\cosh \left(\frac{\pi}{2 T} r\right)}, \text { with } 0 \leq r \leq R
$$

where $n(0)$ is the refractive index along the cylinder axis. This lens is also called "hyperbolic cosine lens" in [6] because of its refractive index distribution or "constant thickness Luneburg lens" in [7] since the thickness of the lens (the height of the cylinder) is fixed contrary to the classical cylindrical Luneburg lens used for 2D focusing.

Note also that the gradient index distribution of a Mikaelian lens has an axial symmetry as opposed to central for Luneburg and Maxwell fish-eye law which may be easier to manufacture. Regarding the properties of the lens, geometrical optics predicts that the Mikaelian lens transforms a point source into a beam of parallel rays as illustrated in Fig. 1(a,b). The near field mapping of Fig. 1(c) shows that a plane wave impinging on one side of the cylinder is focused on a point at the opposite side.

Finally, it is important to point out that the ratio $T / R$ has a direct impact on the refractive index dynamic. As plotted in Fig. 2, the thicker the lens w.r.t. its radius, the smaller the refractive index (and therefore permittivity) variation. Indeed, the ray path length differences are then less important. For a thin lens $(T=R)$, the permittivity inside the dielectric varies from a factor 1 to more than 5 whereas for a thick lens $(T=5 R)$, it goes only from 1 to 1.11 .

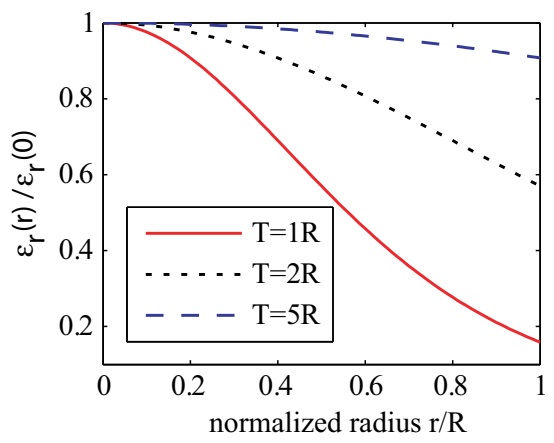

Fig. 2. Relative permittivity distribution of a dielectric Mikaelian lens as a function of the normalized radius: influence of of the ratio thickness over radius of the lens $T / R$.

\section{MANUFACTURING OF GRADIENT InDEX LENSES}

Many ways have been proposed to create gradient index lenses.

Gradient index lenses have first been fabricated using homogeneous dielectric shells to approximate by steps the continuous refractive index distribution [8]. Later, the desired permittivity profile of Luneburg lenses has been obtained by controlling the hole density in a dielectric as detailed in [9]. All these techniques are expensive in terms of fabrication time and cost. More recently, printed planar Luneburg lenses have been proposed. The refractive index of the Luneburg lens is controlled through a combination of meandering crossed microstrip lines and varying their widths in [10]. A planar Luneburg lens has also been realized using a variable printed metasurface in [11]. The desired refractive index is obtained by modulating the surface impedance inside a parallel-plate structure.

Recently, an ingenious technological process has been developed to control the permittivity of foam materials [12], [13]. By changing the ratio between the core material of the foam 


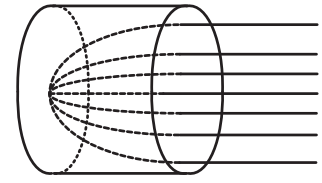

(a)

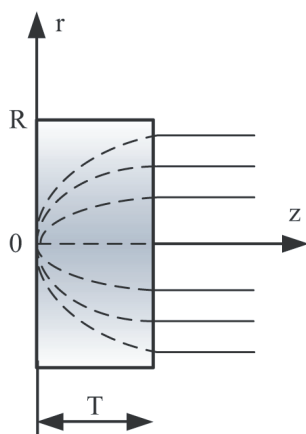

(b)

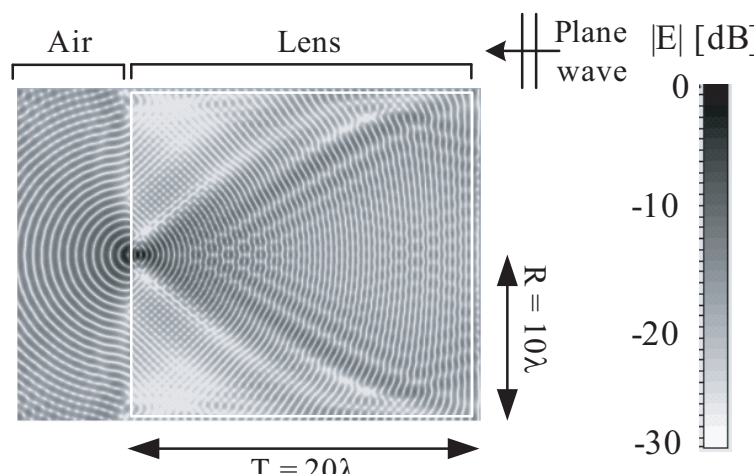

(c)

Fig. 1. (a,b) Ray tracing inside a Mikaelian lens and (c) near electric field mappings computed by CST Microwave Studio of a plane wave impinging on a Mikaelian lens.

and its gas (i.e. by pressing more or less the foam) it is possible to control, up to a certain extent, the permittivity of the foam. More details on the pressing process and the relation between the foam density and its permittivity are given in [13]. This process is a cheap way to easily manufacture very lightweight gradient index lenses. It has already been successfully implemented for Luneburg lenses [14] and is here applied to Mikaelian lenses.

\section{Numerical Focusing PERFormances}

The radiation performances of Mikaelian lenses are investigated and numerically compared to those of Luneburg lenses. The 3D full wave commercial software CST Microwave Studio is used to compute the radiation characteristics of the lens antennas.

The directivity and aperture efficiency of ideal Mikaelian and Luneburg lenses are compared for various lens diameters in Fig. 3. Let us recall that the aperture efficiency is the ratio between the directivity of the lens antenna and the one of a constant field circular aperture of the same diameter. Both lenses are composed of 20 homogeneous dielectric shells to approximate the ideal continuous gradient index. The Mikalian lens has a central relative permittivity $\epsilon_{r}(0)$ of 2 and a thickness $T$ equal to $2 R$. The lenses are fed by a circular open ended waveguide of diameter $2.85 \mathrm{~mm}$ whose directivity alone is $8.1 \mathrm{~dB}$.

These radiation characteristics show that, roughly speaking, both lenses behaves similarly. It seems that the Luneburg lens antennas performs better than the Mikaelian lens for large diameters (above $20 \lambda$ ) whereas the opposite happens for small diameter (below $15 \lambda$ ). However, caution must be taken when interpreting these results since the directivity and consequently the aperture efficiency are relatively sensitive to the position of the antenna with respect to the lens.

\section{EXPERIMENTAL RADIATION PERFORMANCES IN MiLlimeter WAVES}

\section{A. Lens Antenna Prototype}

A foam based planar Mikaelian lens of thickness $T=$ $2 R=56 \mathrm{~mm}$ and height $3 \mathrm{~mm}$ has been manufactured. The lens diameter (or rather width for the planar version) is equal

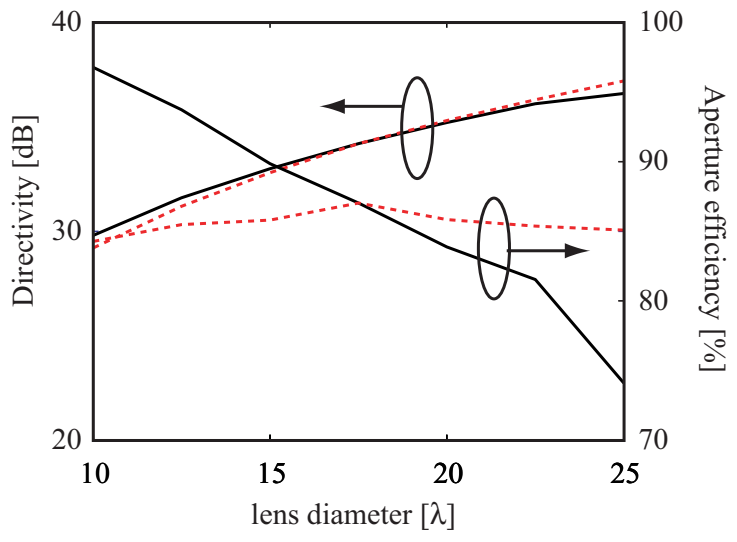

Fig. 3. Directivity and aperture efficiency as a function of the lens diameter for the ideal Mikaelian (solid line) and Luneburg (dashed line) lens fed by a circular waveguide.

TABLE I. CHARACTERISTICS AT $60 \mathrm{GHz}$ OF THE MANUFACTURED MIKAELIAN LENS

\begin{tabular}{ccc}
\hline \hline$r_{i}[\mathrm{~mm}]$ & $\varepsilon_{i}$ & $\tan \delta_{i}$ \\
\hline 2.8 & 2.16 & 0.017 \\
5.6 & 2.14 & 0.016 \\
8.4 & 2.09 & 0.016 \\
11.2 & 2.01 & 0.015 \\
14 & 1.92 & 0.015 \\
16.8 & 1.81 & 0.014 \\
19.6 & 1.69 & 0.013 \\
22.4 & 1.56 & 0.012 \\
25.2 & 1.43 & 0.009 \\
28 & 1.30 & 0.008 \\
\hline \hline
\end{tabular}

to $11.2 \lambda$ at $60 \mathrm{GHz}$.

The lens is made from the foam material Airex PXc245 [15]. Without being pressed the properties of the foam are characterized at $60 \mathrm{GHz}: \epsilon_{r}=1.31$ and $\tan \delta=0.008$.

The permittivity law of the Mikaelian lens is approximated by 10 values given in Table II which correspond to the 10 heights before pressing shown in Fig. 4(a). The lens is fed by a WR15 open ended waveguide operating in the V-band (see Fig. 4(b)). 


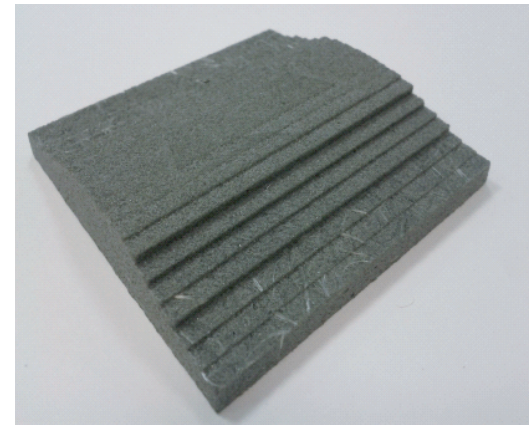

(a)

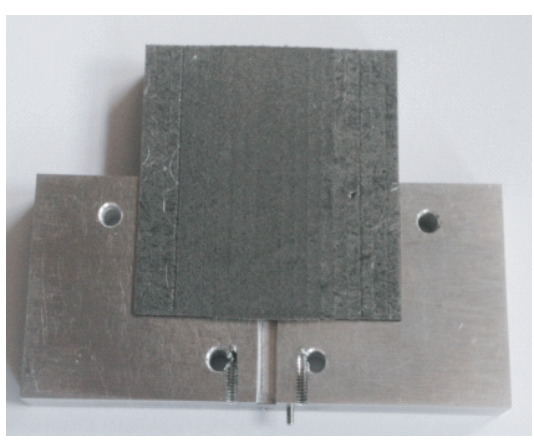

(b)

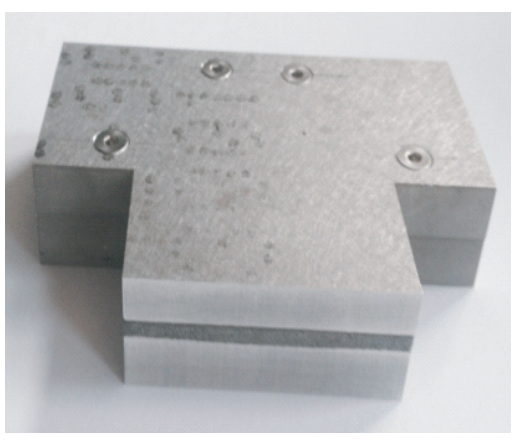

(c)

Fig. 4. Pictures of the Mikaelian lens: (a) before being pressed and (b) pressed inside its mechanical support including the feeding waveguide. (c) Full lens antenna system.

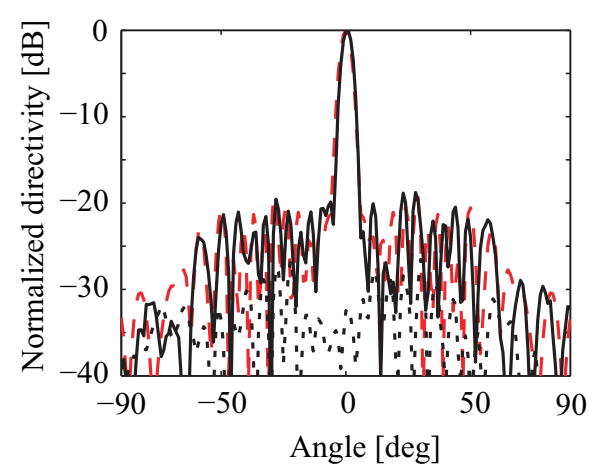

(a)

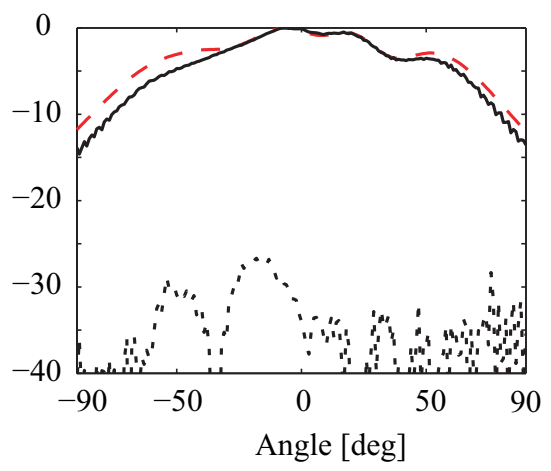

(b)

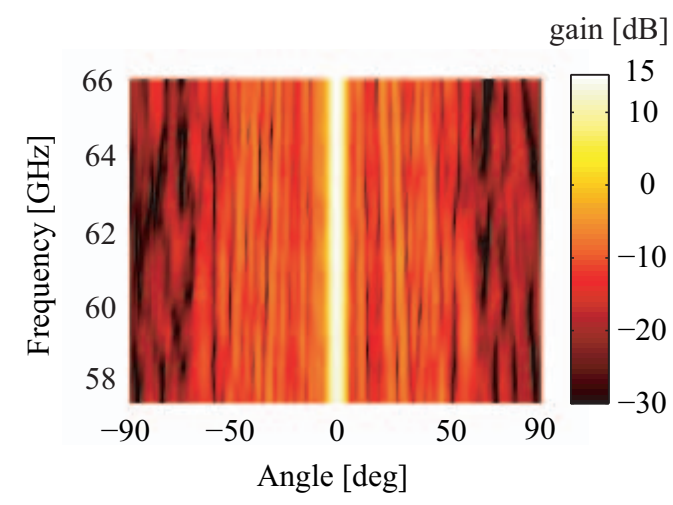

(c)

Fig. 5. Radiation performances of the Mikaelian lens antenna. Normalized far field pattern at $60 \mathrm{GHz}$ in the (a) H- and (b) E-planes: measurements (solid line), simulation (dashed line). (c) Measured gain as a function of the frequency.

\section{B. Experimental Results}

The measured and simulated radiation patterns of the Mikaelian lens antenna at $60 \mathrm{GHz}$ are plotted in Fig. 5(a,b). A fairly good agreement is obtained between simulation and measurements for both E- and H-plane. In the H-plane, the measured half power beamwidth is equal to $4.4^{\circ}$, sidelobes are below $-19 \mathrm{~dB}$ and the cross polarization level is below $25 \mathrm{~dB}$. Note that the asymmetry in the E-plane is due to the non-symmetry of the mechanical support. The gain patterns in the H-plane are plotted as a function of the frequency in Fig. 5(c). They confirm the expected broadband behavior of the lens antenna and show that the Mikaelian permittivity law is properly respected. The measured gain and loss efficiency (gain over directivity) are plotted as a function of the frequency in Fig. 6. The gain increases from about $14 \mathrm{~dB}$ at $57 \mathrm{GHz}$ to $15 \mathrm{~dB}$ at $66 \mathrm{GHz}$ whereas the loss efficiency is between 35 and $39 \%$. This low value of the loss efficiency are due to the relatively high losses of the foam especially when pressed (see the loss tangent in Table II).

\section{CONCLUSION}

The design principles and performances of Mikaelian lens antennas have been investigated. A novel way to create a cheap and lightweight permittivity distribution from foam
TABLE II. Characteristics OF THE MANUfaCtURED MiKaElian LENS

\begin{tabular}{ccc}
\hline \hline$r_{i}[\mathrm{~mm}]$ & $\varepsilon_{i}$ & $\tan \delta_{i}$ \\
\hline 2.8 & 2.16 & 0.017 \\
5.6 & 2.14 & 0.016 \\
8.4 & 2.09 & 0.016 \\
11.2 & 2.01 & 0.015 \\
14 & 1.92 & 0.015 \\
16.8 & 1.81 & 0.014 \\
19.6 & 1.69 & 0.013 \\
22.4 & 1.56 & 0.012 \\
25.2 & 1.43 & 0.009 \\
28 & 1.30 & 0.008 \\
\hline \hline
\end{tabular}

has been proposed and applied to manufacture the lens. The experimental results at $60 \mathrm{GHz}$ validate the foam technique and potentialities of the lens.

Although the Mikaelian lens does not have the same ability as Luneburg lenses to form multiple beams, its cylindrical shape makes it very attractive for integrated designs.

More details are provided in [16].

\section{ACKNOWLEDGMENT}

The authors thank Hervé Merlet and Dr. Philippe Le Bars for fruitful discussions. 


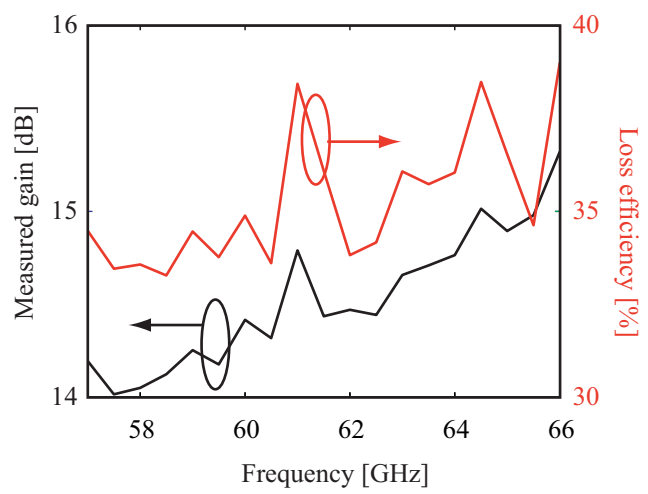

Fig. 6. Measured gain and loss efficiency of the Mikaelian lens antenna as a function of the frequency.

\section{REFERENCES}

[1] H. Mosallaei and Y. Rahmat-Samii, "Nonuniform Luneburg and 2-shell lens antennas: Radiation characteristics and design optimization," IEEE Trans. Antennas Propag., vol. 49, no. 1, pp. 60-69, Jan. 2001.

[2] Y.-J. Park and W. Wiesbeck, "Offset cylindrical reflector antenna fed by a parallel-plate Luneburg lens for automotive radar applications in millimeter-wave," IEEE Trans. Antennas Propag., vol. 51, no. 9, pp. 2481-2483, Sep. 2003

[3] B. Fuchs, O. Lafond, S. Rondineau, and M. Himdi, "Design and characterization of half maxwell fish-eye lens antennas in millimeter waves," IEEE Trans. Microwave Theory and Techniques, vol. 54, no. 6, pp. 2292-2300, June 2006.

[4] A.L. Mikaelian, "Application of Laminated Media for Wave Focusing," Journal of Dokladi. Akademii Nauk, vol. LXXXI, no.4, 1951.

[5] A.L. Mikaelian, "Self focusing media with variable index of refraction," E. Wolf, Progress in optics XVII, North Holland, 1980.

[6] Y.T. Lo and S.W. Lee, "Antenna Handbook: antenna theory," vol. II, Van Nostrand Reinhold: New York, 1993, ch. 16, pp. 53.

[7] H. Jasik, "Antenna Engineering Handbook," New York: McGraw-Hill, 1961, ch. 15 , pp. 18-19.

[8] G.D.M. Peeler and H.P. Coleman, "Microwave Stepped-Index Luneburg Lenses,” IRE Trans. Antennas Propag., vol. 6, no. 2, pp. 202-207, April 1958.

[9] S. Rondineau, M. Himdi, and J. Sorieux, "A sliced spherical Luneburg lens,” IEEE Antennas Wireless Propag. Lett., vol. 2, pp. 163-166, 2003.

[10] C. Pfeiffer and A. Grbic, "A Printed, Broadband Luneburg Lens Antenna," IEEE Trans. Antennas Propag., vol. 58, no. 9, pp. 3055-3059, Sep. 2010.

[11] M. Bosiljevac, M. Casaletti, F. Caminita, Z. Sipus and S. Maci, "NonUniform Metasurface Luneburg Lens Antenna Design," IEEE Trans Antennas Propag., vol. 60, no. 9, pp. 4065-4073, Sep. 2012.

[12] H. Merlet, P. Le Bars, O. Lafond, and M. Himdi, "Manufacturing method of a dielectric material and its application to millimeter-waves beam forming antenna systems," patent WO2013083794, June 2013.

[13] J. Bor, O. Lafond, H. Merlet, P. Le Bars, and M. Himdi, "Technological process to control the foam dielectric constant - application to microwave components and antennas," IEEE Trans. Compon. Packag. Manuf. Technol., vol. 4, no. 5, pp. 938-942, 2014.

[14] J. Bor, O. Lafond, H. Merlet, P. Le Bars, and M. Himdi, "Foam based Luneburg Lens Antenna at $60 \mathrm{GHz}$," Progress in Electromagnetic Research B, vol. 44, pp. 1-7, 2014.

[15] Airex Baltek, http://www.corematerials.3acomposites.com/.

[16] J. Bor, B. Fuchs, O. Lafond and M. Himdi, "Design and Characterization of a Foam-based Mikaelian Lens Antennas in Millimeter Waves," submitted to International Journal of Microwave and Wireless Technologies in 2014. 